\title{
The Effect of Sustained Transparency on Electoral Accountability
}

\author{
Guy Grossman ${ }^{\dagger}$ Kristin Michelitch ${ }^{\ddagger}$ Carlo Prato ${ }^{\S}$
}

March 2, 2022

Word count: 9,993

\begin{abstract}
Transparency is expected to strengthen electoral accountability. Yet, initiatives disseminating politician performance information directly prior to elections have reported disappointing results. We argue that to be effective transparency needs to be sustained: the dissemination of politician performance information needs to occur early, regularly, and predictably throughout the term. Using a formal model of electoral accountability under non-programmatic and uneven party competition, we study how sustained transparency impacts a string of decisions by various actors in advance of elections: incumbents' running choices, party nomination strategies, and potential challengers' entry decisions. We show how these effects shape the candidate slate and ultimately electoral outcomes, conditional on incumbent performance and the incumbent party's relative strength. We test our theory using a field experiment involving 354 subnational constituencies in Uganda, and find robust support to the idea that sustained transparency can improve electoral accountability even in weakly institutionalized electoral settings.
\end{abstract}

\footnotetext{
${ }^{*}$ We are grateful to the Democratic Governance Facility for its generous funding of the ACODE intervention and research components. Kristin Michelitch is grateful to the Carnegie Corporation of New York for additional financial support. We thank Frédéric Cochinard, Shuning Ge, Christine Goldrick, Ana Garcia Hernandez, Austin Walker, Areum Han, and Maximilian Seunik for invaluable research assistance. This project would not have been possible without our ACODE team partners, especially Godber Tumushabe, Arthur Bainomugisha, Eugene Ssemakula, Lillian Tamale, Phoebe Atakunda, Naomi Kabarungi, and Naomi Asimo. We received valuable feedback from EGAP, CAPERS, WPSA, the Formal Theory Virtual Seminar, Vanderbilt University, European Union Institute, and Toulouse's School of Economics, as well as from Sandy Gordon, Alan Wiseman, Guillermo Toral, Dmitri Landa, Brad Smith, John Marshall, Giovanna Invernizzi and Annabelle Wittels. This project received research permits from Uganda's National Council for Science and Technology and the President's office, as well as IRB clearance for the research arm of Innovation for Poverty Action. We pre-registered our analysis plan at EGAP. The Supplemental Information includes a list of adaptations from the original plan.

${ }^{+}$Professor, University of Pennsylvania. 133 S. 36th Street, Philadelphia, PA 19104. Email: ggros@sas.upenn.edu

${ }_{\ddagger}$ Andrew Carnegie Fellow, Assistant Professor, Vanderbilt University. Commons Center PMB 0505, 230 Appleton Place, Nashville, Tennessee 37203-5721. Email: kristin.michelitch@vanderbilt.edu

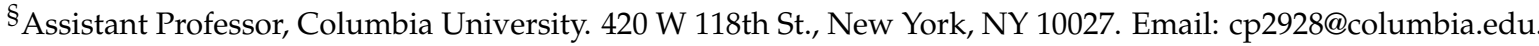


Electoral accountability hinges on the availability of information about politicians' performance. Yet, in many low-income country settings such information is scarce. Despite a growing number of transparency initiatives, many of which are funded through foreign assistance, the empirical relationship between transparency and electoral accountability remains "uncertain" (Fox, 2007), with a recent set of coordinated field experimental studies yielding null results (Dunning et al., 2019). Understanding the conditions under which transparency initiatives can improve electoral accountability thus remains a question of paramount academic and policy importance.

With few exceptions, previous scholarship has focused on one-shot dissemination of politician performance information directly prior to elections (e.g., Chong et al., 2015). In this paper, we argue and show that sustained transparency - the dissemination of such information early, regularly, and predictably throughout the electoral cycle-can play a critical role in strengthening electoral accountability. We study, both theoretically and empirically, how sustained transparency affects a string of pre-election decisions by politicians, potential challengers, and political parties that ultimately affect the slate of candidates presented to voters.

We formally study sustained transparency in a context common in low-income countries, where (i) elections revolve around valence rather than wedge issues, (ii) politicians are primarily motivated by winning office but can also be visibility-motivated by candidacy per se, and (iii) there is considerable variation in relative party advantage-i.e., parties' (relative) appeal and organizational capacity, which affects their ability to recruit strong candidates. Of course, these electoral conditions could exist also in higher-income settings, especially at the local level. We model relative party advantage as the perceived ability of the incumbent party's candidates at the start of the electoral term. These perceptions are updated based on incumbent performance signals, and transparency improves their accuracy. This conceptualization allows us to explore the effect of transparency in settings ranging from competitive to considerably asymmetric (where one party enjoys a large advantage over the others).

Our formal analysis shows that relative party advantage moderates the effect of sustained transparency on electoral outcomes. For instance, when relative party advantage is low, the running decisions of potential challengers does not respond to changes to voters' perceptions of the incumbents' ability. For this reason, when the relative advantage of the incumbent party is low, we 
expect transparency to have little effect on the number of challengers facing an incumbent seeking reelection, and a weaker effect on incumbents' election prospects.

The role of transparency in improving electoral accountability is thus more nuanced than previously considered. Conventional theories of electoral accountability focus on incumbents and voters. In those models, re-election depends on whether the resulting perceptions of the incumbent's ability exceed an exogenous standard (the perceived ability of a non-strategic challenger). In our model, sustained transparency also affects party leaders' nomination decisions and potential challengers' entry choices, and thus the candidate slate prior to vote choice. The anticipation of these electoral forces shapes incumbents' effort choices and their decisions to run for reelection. Hence, transparency not only influences voters' perceptions of incumbents' ability, but also (i) whether they reach the general election, and (ii) the standard against which voters will measure incumbent performance (a function of challenger entry).

We test the empirical implications of our model using data from a field experiment conducted with 354 local government representatives in Uganda, a setting in tune with our formal model. We collaborate with Advocates Coalition for Development and Environment (ACODE), a nonpartisan Ugandan NGO that creates annual performance scorecards for district councilors. ACODE disseminates the scorecards at yearly events attended by local elites. During the 2011-2016 cycle, half of the incumbent councilors were randomly selected to have their scorecards disseminated directly to communities in their constituencies. In line with our model, Grossman and Michelitch (2018) find that such dissemination improved incumbents' scorecard performance, but only outside of party strongholds. By fielding a politician survey and culling official electoral returns, this study assesses the subsequent effect of the program on incumbent running decisions, party nominations, challenger entry, and vote choice.

Results are broadly consistent with our theory's predictions. Transparency increases the reelection probability of incumbents with above-median performance by 4.3 percentage points (pp.) and decreases it for incumbents with below-median performance by $15.1 \mathrm{pp}$. When conditioning on winning the party nomination, and considering incumbents' relative party advantage, these effects are stronger-in line with the model predictions. Citizens' vote choice, potential challengers' entry decisions and (to a lesser extent) parties' nomination strategies all contribute to these effects. 
Sustained transparency thus has a genuine potential to improve electoral accountability, even in settings with large asymmetries in parties' relative strength.

This study contributes to the theoretical and empirical scholarship on electoral accountability. Theoretically, we formally study how endogenous challenger entry and party nomination decisions shape the relationship between voter information and electoral accountability. ${ }^{1}$ Against a backdrop of null findings from several transparency campaigns undertaken directly prior to elections (e.g., Cruz, Keefer and Labonne, 2021), our study provides a rationale behind the more positive results in studies in which transparency initiatives occurred sufficiently early in the term to trigger improvements in politician performance (e.g., in spending discretionary funds (Ofosu, 2019), and tax compliance (Malik, 2020)). ${ }^{2}$

Second, we contribute to the literature on party nominations and candidate entry (for a review, see Gulzar, 2021) by introducing two novel elements-transparency and (relative) party advantage. Past work has largely focused on high-income democracies and generally downplayed (or overlooked) the potential role of a polity's level of transparency. ${ }^{3}$ This study, instead, contribute to the literature on uneven party competition in weakly institutionalized electoral settings (Weghorst, 2022).

Finally, our findings are consistent with work suggesting that retrospective voting does affect at least some voters in developing country settings (e.g., Harding, 2015). Alongside the introduction of debates (Brierley, Kramon and Ofosu, 2020) or policy platform information (Platas and Raffler, 2021), this study suggests that sustained transparency may encourage a more performancebased form of electoral competition in developing countries.

\footnotetext{
${ }^{1}$ Recent formal theories generally focus on trade-offs between moral hazard and adverse selection (Duggan and Martinelli. 2020), and the effect of identity and bounded rationality (Prato and Wolton. 2016). We also join Izzo, Dewan and Wolton (2020) in directly responding to conceptual gaps in recent empirical findings.

${ }^{2}$ Other barriers to strengthen accountability via transparency regard the potential for politicians to discredit performance information (Humphreys and Weinstein. 2012), prevent its dissemination (Sircar and Chauchard. 2019), or increase vote-buying to offset its effect (Cruz, Keefer and Labonne. 2021). Scholars also note potential barriers to citizens' use of information, such as uncertainty over attribution (Martin and Raffler, 2021), motivated reasoning (Adida et al. 2017), the salience of politician performance indicators (Bhandari, Larraguy and Marshall. 2021), and coordination problems (Arias et al. 2019).

${ }^{3}$ Theoretical scholarship of candidacy entry focuses on ideology and competence (Gordon and Landa, 2009) and private sector opportunities (Caselli and Morelli. 2004). With its focus on rent-seeking, Svolik (2013) represents an exception. Empirical studies of candidacy entry have focused on the role of dynasties (Cruz, Labonne and Querubin, 2017), party leaders' information (Gulzar, Hai and Paudel, 2021), and potential candidates' opportunity costs (Grossman and Hanlon, 2014).
} 


\section{A Theory of Sustained Transparency and Accountability}

We define sustained transparency as early, predictable, and regular dissemination of incumbent performance information throughout their term. As a result of being early and predictable, sustained transparency should influence (i) incumbents' effort choices, (ii) their decision to run for reelection, (iii) their ability to secure her party's (re)nomination, (iv) entry decisions by potential challengers, and (v) constituents' vote choice. Our modeling choices are informed by documented features of electoral politics in weakly institutionalized democracies and hybrid regimes.

First, citizens and parties have limited information about local incumbent performance (Gulzar, Hai and Paudel, 2021), partly due to the narrow reach of independent news media. NGOs can fill this void, especially at the subnational level (Grossman and Michelitch, 2018) where transparency is less susceptible to government interference (Hollyer, Rosendorff and Vreeland, 2018).

Second, party competition revolves around valence issues (e.g., candidate competence) rather than wedge issues (Bleck and Van de Walle, 2018). Since parties are generally not ideological, incumbents who lose their party nomination can switch parties at relative ease, or (if allowable) run as independents (Ichino and Nathan, 2013). Further, while candidates derive benefits from holding office, they can also derive status ("visibility") merely from candidacy (Weghorst, 2022).

Third, there is considerable variation in the strength of political parties, especially at the subnational level (Hiskey and Moseley, 2020). In many low-income countries (including Uganda), multiparty competition followed a period of single-party rule. In these cases, there is considerable regional variation in opposition parties' ability to contest power. In certain (usually marginalized) areas, opposition parties dominate local politics; in other areas, they compete with the nationally dominant party; in other areas, the gap in name recognition, resources, and organizational capacity is insurmountable. To capture these asymmetries, we allow incumbents to differ in their relative party advantage, modeled as politicians' initial perceived ability. Over the cycle, voters update these perceptions based on performance signals whose accuracy increases with transparency. ${ }^{4}$ Our notion of party advantage does not include voter intimidation, repression, or election rigging. As

\footnotetext{
${ }^{4}$ From a modeling standpoint, relative party advantage is similar to "partisan bias" in Gordon and Landa (2009) and "partisan advantage" in Prato and Wolton (2018), though in these two studies asymmetries stem from geographic variation in voters' attitudes on positional issues.
} 
(2) Running Decision:

- I's reputation updated

- I's running choice
(4) General Election:

- each $i$ 's reputation revealed

- each $i$ chooses whether to run

- voter chooses one candidate
(1) Governance:

- I observes her ability

- I's effort choice

- performance signal is realized
(3) Party Nomination:

- $R^{\prime}$ s reputation revealed

- $L$ 's selection choice

- I's independent running choice

Figure 1: Timeline

such, our model does not apply to authoritarian contexts where the deployment of these tools prevents any form of electoral accountability.

\section{Model Primitives}

Actors. The model features a representative voter, an incumbent $I$, her party leader $L$, and $n$ potential general election challengers (indexed by $i$ ). $L$ and $I$ 's party also includes a non-strategic reservation candidate $R$.

Each politician can be high-ability $(\theta=1)$ or low-ability $(\theta=0)$, which is privately observed. ${ }^{5}$ $\mu_{j} \in[0,1]$ denotes politician $j$ 's reputation: the public belief that $j$ is high-ability. Each potential general election challengers' reputations are independently drawn from the distribution $F(\cdot)$-a truncated normal with parameters $(1 / 2, \sigma)$ and support $[0,1]$. The incumbent $I$ begins the term with a reputation of $\mu_{0} \in(0,1)$ and the reputation of the reserve candidate $R$ is drawn from a truncated normal distribution $F_{R}(\cdot)$ with parameters $\left(\mu_{0}, \sigma\right)$ and support $[0,1] . \mu_{0}$ captures, in a reduced form, a party's organizational capacity, its ability to recruit candidates, and its local electoral appeal.

The game is divided into four stages, summarized in Figure 1: Governance, Incumbent Running Decision, Party Nomination, and General Election.

Governance. $I$ privately observes her ability $\theta_{I} \in\{0,1\}$, then chooses effort $e \in[0,1]$ at $\operatorname{cost} C(e)=$

\footnotetext{
${ }^{5}$ The assumption that party leaders and voters have the same information about candidate ability is for expositional simplicity. Our insights go through as long as leaders cannot credibly transmit their private information to voters, which in our empirical context is plausible.
} 
$\frac{e^{1+\gamma}}{1+\gamma}$, with $\gamma>1$. Effort and ability jointly improve the realization of performance $\pi$, which can be high $(\pi=h)$, with probability $\operatorname{Pr}(\pi=h \mid \theta, e)=e \frac{1+\theta}{2}$, or low $(\pi=l)$. I's performance cannot be perfectly monitored. All actors, instead, observe a public signal $\mathrm{s} \in\{l, h\}$ with precision $\tau \in[0,1]$, so that $\operatorname{Pr}(\mathrm{s}=\pi)=\frac{1+\tau}{2}$. NGO transparency initiatives increase the value of $\tau$. Following the performance signal, the public updates $I^{\prime}$ s reputation from $\mu_{0}$ to $\mu_{I}(\mathrm{~s})$ using Bayes rule.

Incumbent Running Decision. After observing s, $I$ decides whether to run for reelection $\left(r_{I}=1\right)$ or not $\left(r_{I}=0\right)$. Running is associated with a cost $k \in(0,1)$, capturing the time and resources required for a campaign.

Party Nomination. The reserve candidate's reputation $\mu_{R}$ is drawn from $G$ and publicly observed. If $I$ chooses not to run, $R$ becomes the nominee (denoted by $N$, so $R=N$ ). If instead $I$ chooses to run, $L$ chooses whether to nominate $R$ and de-select $I\left(d_{L}=1\right.$, resulting in $\left.N=R\right)$ or $I\left(d_{L}=0\right.$, resulting in $N=I) .{ }^{6}$ If $L$ nominates $R, I$ can quit the party $\left(q_{I}=1\right)$ and run as an independent in the general election at an additional $\operatorname{cost} \varepsilon$, drawn from a distribution $F_{\varepsilon}$ with mean zero and support $[-\bar{\varepsilon}, \bar{\varepsilon}]$. Negative values of $\varepsilon$ capture the gain in status and visibility associated with candidacy.

General Election. Each potential general election challenger $i$ observes her own reputation $\mu_{i} \in$ $[0,1]$ and chooses whether to run for election $\left(r_{i} \in\{0,1\}\right)$. After observing the slate of candidates, the voter elects the candidate with the highest reputation among those running. As a result, the party candidate $N \in\{I, R\}$ wins if and only if she has the highest reputation: ${ }^{7}$

$$
\mu_{N} \geq \max \left\{\max _{i}\left\{\mu_{i} r_{i}\right\}, q_{I} \mu_{I}\right\}
$$

Payoffs. We assume that the incumbent party leader $L$ cares about keeping the seat (its value is normalized to one) and experience an additional net payoff $\zeta \in\{-1,0,1\}$ from keeping the incumbent, capturing additional considerations that voters do not directly value, such as party loyalty. We assume that the incumbent is uncertain about the value of $\zeta$ and let $\chi_{\zeta}=\operatorname{Pr}(\zeta)$. Let $W$ denote the general election winner and $1\{\cdot\}$ denote the indicator function. We have $u_{L}=$ $\mathbf{1}\{N=W\}+\zeta \mathbf{1}\{N=I\}$.

\footnotetext{
${ }^{6}$ This reduced-form nomination captures the wide spectrum of candidate selection procedures observed in our context (Ichino and Nathan, 2013), ranging from well-organized primaries (in which case $L$ captures the median primary voter) to informal closed-door discussions (in which case $L$ captures the choice of party elites).

${ }^{7}$ Ties in this model are zero probability events, so we do not specify how they are resolved.
} 
Potential general election challengers value being elected and suffer the net cost $k$ if they run. Hence, $i$ 's payoff is given by $u_{i}=\mathbf{1}\{i=W\}-r_{i} k$. The incumbent similarly values winning the election. She can reach it as the party nominee with probability $1-d_{L} ;$ or as an independent with probability $d_{L} q_{I}$, net of the cost of running (with its uncertain component $\varepsilon$ ) and the cost of effort. Her payoff is then $u_{I}=r_{I}\left(\mathbf{1}\{I=W\}-k-d_{L} q_{I} \epsilon\right)-C(e)$. To ensure tractability, we assume that $\sigma$ (the variance of $F$ and $F_{R}$ ) is large enough, that $\bar{\varepsilon}$ is small enough, and that $\tau$ is not too large. ${ }^{8}$

Equilibrium. We study sequential equilibria with the restriction that politicians' running decisions can only depend on their reputation. ${ }^{9}$ An equilibrium specifies a strategy profile $\left\{e_{I}, r_{I}, d_{L}, q_{I}, r_{i}\right\}$ and a belief system $\left\{\mu_{I}(l), \mu_{I}(h)\right\}$.

\section{Equilibrium Analysis}

We proceed by backward induction: first, we begin with the general election, then the party nomination stage, then the incumbent's running decision, and finally the governance stage.

General Election. A potential challenger runs if and only if her winning probability exceeds the cost of running $k$. When making her entry decision, $i$ can observe the reputation of the party nominee $N$ and, when he is running as an independent, that of the incumbent $I$. $i$ can only win if her reputation exceeds them, i.e., if $\mu_{i}>\max \left\{\mu_{N}, q_{I} \mu_{I}\right\}$. This is the outsider hurdle. This is necessary but not sufficient to win: $i$ 's reputation also needs to exceed that of the other general election candidates, whose reputation and behavior $i$ can only conjecture. Given these conjectures, her reputation needs to generate a sufficiently large winning probability to compensate for the cost $k$. This is the contestability hurdle. In SI H, we show that this is equivalent to: $\mu_{i} \geq F^{-1}\left(k^{\frac{1}{n-1}}\right)$. Combining outsider and contestability hurdle yields our first result:

Lemma 1 A potential challenger $i$ runs if and only if her reputation exceeds both outsider and contestability hurdles, i.e., when

$$
\mu_{i} \geq \widehat{\mu} \equiv \max \left\{F^{-1}\left(k^{\frac{1}{n-1}}\right), \mu_{N}, q_{I} \mu_{I}\right\} .
$$

\footnotetext{
${ }^{8}$ See SI H for details and formal statements of these assumptions.

${ }^{9}$ This assumption allows us to focus on symmetric equilibria in the challenger entry subgame and to abstract from situations in which a politician's running decision is itself informative about her ability, and about the incumbent's ability (Gordon and Landa. 2009) .
} 
Party nomination. By the same reasoning of Lemma 1, an incumbent who lost the party nomination quits the party and runs as an independent if she is either visibility-motivated $(\varepsilon<0)$ or when her reputation exceeds that of the party nominee $R$ (see Lemma H1 in SI H). When the incumbent $I$ chooses to run for reelection, the party leader's decision between $I$ and the replacement candidate $R$ depends on (i) his non-electoral value of keeping the incumbent (captured by the bias $\zeta)$ and (ii) the electoral value of keeping $I$, i.e., how nominating $R$ changes the party's likelihood of keeping the seat. Under the assumptions, the party leader confirms the incumbent if (i) the non-electoral value of the incumbent is high (i.e., the bias favors the incumbent) or (ii) the leader is unbiased and $I$ has a higher reputation.

Lemma 2 The party leader replaces the incumbent if either he is biased against her $(\zeta=-1)$, or if he is unbiased and the replacement candidate has a higher reputation $\left(\zeta=1\right.$ and $\left.\mu_{I}>\mu_{R}\right): d_{L}\left(\mu_{I}, \mu_{R}, \zeta\right)=$ $\mathbf{1}\{\zeta=1\}+\mathbf{1}\{\zeta=0\} \mathbf{1}\left\{\mu_{I} \geq \mu_{R}\right\}$.

Incumbent's Running Decision. After observing her performance signal s, an incumbent runs for reelection if and only if the expected payoff of doing so exceeds the running cost $k$. In SI H, we show that this expected payoff is strictly increasing in her reputation $\mu_{R} \cdot{ }^{10}$ We then obtain that the incumbent runs if and only if her reputation exceeds a threshold $\mu^{*}$ :

Lemma 3 There exists $\mu^{*} \in(0,1)$ such that the incumbent runs for reelection if and only if $\mu_{I} \geq \mu^{*}$.

Combining Lemmas 1-3, we can characterize $V_{\mathrm{s}}$, the incumbent's expected payoff as a function of her signal realization ( $\mathrm{SI} \mathrm{H}$, page 3). The incumbent's optimal effort choice then solves $e(\theta)=$ $\arg \max _{e \in[0,1]} \mathbf{E}\left\{V_{\mathbf{s}} \mid e ; \theta\right\}-C(e)$. In SI H, we show that the value of effort is proportional to the difference $V_{h}-V_{l}$, i.e., to how much the increase reputation of a high performance signal improves the incumbent's chances. We also show that this difference crucially depends on relative party advantage (the prior reputation of the incumbent and the expected reputation of her internal challenger). Specifically, we identify two thresholds for relative party advantage (one for each possible signal realization) above which $I$ runs for reelection:

\footnotetext{
${ }^{10} I^{\prime}$ s expected payoff depends on (i) how her reputation compares to $\mu_{R}$, (ii) the party leader's bias $\zeta$, (iii) her non-electoral motivation $\varepsilon$, and (iv) how her reputation compares to that of her general election opponents.
} 
Lemma 4 There exist thresholds $\underline{\mu}, \bar{\mu}$ for relative party advantage such that an incumbent

(i) never runs for reelection when $\mu_{0}<\underline{\mu}$;

(ii) runs for reelection only after a positive performance signal when $\mu_{0} \in[\underline{\mu}, \bar{\mu}]$;

(iii) always runs for reelection when $\mu_{0}>\bar{\mu}$.

Intuitively, a higher relative party advantage improves the baseline from which the incumbent performance will be evaluated, thereby improving her electoral prospects, and deterring potential general election challengers. A key implication of this result is that performance information is pivotal for I's running decisions only when party advantage is intermediate.

Governance. A consequence of Lemma 4 is that equilibrium effort depends on party advantage $\mu_{0}$. When $\mu_{0}$ is intermediate, effort is most valuable: it increases both the incumbent's probability of running and her winning probability conditional on running. Conversely, when $\mu_{0}$ is large $\left(\mu_{0}>\right.$ $\bar{\mu})$, effort only increases the incumbent's winning probability. When instead $\mu_{0}$ is low $\left(\mu_{0}<\underline{\mu}\right)$, incumbents choose low effort because they anticipate that they will (likely) not run for reelection. In $\mathrm{SI} \mathrm{H}$ we show that effort is indeed quasi-concave in party advantage.

\section{The Effect of Transparency}

How does sustained transparency affect the choices of incumbents, parties, potential opponents, and voters? Since our outcomes of interest are contingent on one another, the model allows us to formulate hypotheses that take this chain of dependence into account. Table 1 summarizes the empirical implications of our theory.

Governance. Under a benchmark of no transparency $(\tau=0)$, the public signal s is uninformative about performance, and so does not change the incumbent's reputation. As a result, effort is not valuable for the incumbent, who then sets it to zero. As transparency increases, the performance signal becomes increasingly more accurate and the incumbent's reputation increasingly sensitive to s: a larger improvement when the signal is high $(\mathrm{s}=h)$ and a larger decline when the signal is low $(\mathrm{s}=l)$. This increases equilibrium effort. Since higher effort increases the difference in performance between types, transparency widens the gap between the two posteriors $\mu_{I}(h)$ and $\mu_{I}(h)$ both directly and indirectly (through effort). 
Proposition 1 An increase in transparency

(i) increases incumbent effort for all abilities and costs of running

(ii) increases the incumbent's reputation conditional on a high performance signal $\mu_{I}(h)$

(iii) decreases the incumbent's reputation conditional on a low performance signal $\mu_{I}(l)$.

Incumbent's Running Decision. Recall that an office seeking incumbent never runs when $\mu_{0}<\underline{\mu}$, always runs when $\mu_{0}>\bar{\mu}$, and only runs after a high signal when $\mu_{0}$ falls in between $\underline{\mu}$ and $\bar{\mu}$. By increasing both effort and the posterior gap $\mu_{I}(h)-\mu_{I}(l)$, higher transparency widens the gap between the two participation thresholds:

Proposition $2 \underline{\mu}$ decreases in transparency and $\bar{\mu}$ increases in transparency.

By Proposition 2, sustained transparency changes the set of incumbents that choose to run for reelection. Specifically, it increases the range of situations in which performance information is pivotal for the incumbent's running decision, as illustrated in Figure $2^{11}$

Figure 2 also illustrates that disregarding the moderating effect of relative party advantage can lead to substantially overstate the effect of transparency on accountability. When the incumbent party has a large advantage (respectively, a disadvantage), greater transparency may be insufficient to deter low-performance incumbents from running for reelection (respectively, to encourage high-performance incumbents to run for reelection). As a result, when party advantage is low $\left(\mu_{0}<\underline{\mu}(\tau)\right)$, increasing transparency encourages high-performers to run; when it is high $\left(\mu_{0}<\bar{\mu}(\tau)\right)$, increasing transparency discourages low-performers from running.

Hypothesis 1 (a) I's running probability weakly decreases in transparency when the signal is low (s=l) and weakly increases in transparency when the signal is high $(\mathrm{s}=h)$;

(b) the drop in running probability when $\mathrm{s}=l$ is strict when party advantage is large (at baseline $\tau, \mu_{0}>\bar{\mu}$ );

(c) the rise in running probability when $\mathrm{s}=h$ is strict when party advantage is small (at baseline $\tau, \mu_{0}<\underline{\mu}$ ).

Party nomination. Sustained transparency increases the accuracy of the public signal (s). Therefore, as $\tau$ increases the incumbent's likelihood of winning the nomination conditional on running

\footnotetext{
${ }^{11} \mu^{*}$ is a function of $\mu_{0}$, but this dependence vanishes as $\sigma$, the scale parameter of the distributions $F$ and $G$, grows.
} 


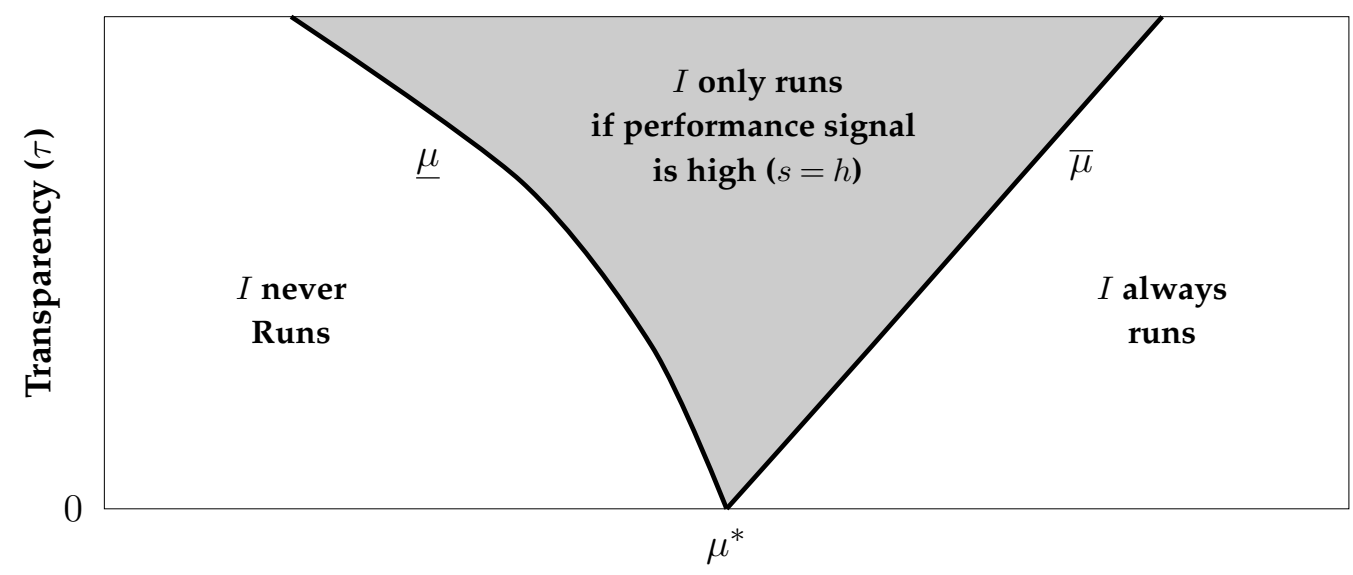

Relative Party Advantage $\left(\mu_{0}\right)$

Figure 2: The running decision of incumbents with high- and low-performance public signals as a function of both sustained transparency $(\tau)$ and relative party advantage $\left(\mu_{0}\right)$.

becomes more sensitive to her performance. This, in turns, enhances high performers' chances to win the party nomination in two ways: first, $\tau$ lowers $\underline{\mu}$, the minimum level of party advantage above which high performers run (Proposition 2); second, $\tau$ increases their reputation conditional on running, thereby reducing the chances that an unbiased party leader prefers to nominate the replacement candidate $R$.

Hypothesis 2 I's probability of winning the nomination (conditional and unconditional on running) decreases in transparency when the signal is low $(\mathrm{s}=l)$ and increases when the signal is high $(\mathrm{s}=h)$.

General Election. In equilibrium, an incumbent reaches the general election when she runs for reelection and she either wins her party nomination or runs as an independent. The likelihood of running and winning the party nomination is then increasing in $\tau$ for high performers and decreasing in $\tau$ for low performers. Due to its effect on her reputation, sustained transparency also affects the general election's results. Specifically, transparency increases the likelihood that high performers win (and low performers lose) the general election. The effect, however, is again moderated by relative party advantage.

By Lemma 1, when an incumbent reaches the general election, potential challengers run only if their reputation exceeds $\max \left\{F^{-1}\left(k^{\frac{1}{n-1}}\right), \mu_{I}, \mu_{R}\right\}$. Transparency then affects the expected number of general election candidates only when the outsider hurdle (which depends on the incum- 
bent's reputation) exceeds the contestability hurdle (which is driven on the cost of running $k$ )-i.e., when party advantage is large enough. For this reason, we expect that the effect of transparency on the number of challengers and the incumbent's winning probability should be stronger when party advantage is larger. ${ }^{12}$

Hypothesis 3 (a) I's winning probability conditional on reaching the general election decreases in transparency when the signal is low $(\mathrm{s}=l)$ and increases in transparency when the signal is high $(\mathrm{s}=h)$;

(b) both the drop (when $\mathrm{s}=l$ ) and the improvement (when $\mathrm{s}=h$ ) in winning probability are larger when party advantage is large ( $\mu \geq \bar{\mu}$ and $\mu \geq \underline{\mu}$, respectively);

(c) transparency has the opposite effect on the expected number of candidates.

\begin{tabular}{|c|c|c|c|c|}
\hline \multirow{2}{*}{$\begin{array}{l}\text { Performance Signal: } \\
\text { Relative Party Advantage: }\end{array}$} & \multicolumn{2}{|c|}{ Low } & \multicolumn{2}{|c|}{ High } \\
\hline & Low & High & Low & High \\
\hline Probability that I runs & $=$ & - & + & $=$ \\
\hline Probability that I wins the party nomination & - & - & + & + \\
\hline Probability that I wins the general election & $=$ & - & $=$ & + \\
\hline Number of candidates & $=$ & - & $=$ & + \\
\hline
\end{tabular}

Table 1: The effect of increasing sustained transparency

\section{Research Design}

We test the model's predictions using data from 20 Ugandan district governments (one level below the national level), where a local NGO (ACODE) assembled and disseminated incumbent performance information during the 2011-2016 term. We examine incumbents' choice of running for reelection, parties' nomination decisions, potential challengers' entry choices, and constituents' vote choices in the 2016 elections.

\footnotetext{
${ }^{12}$ We do not explicitly assume visibility-motivation among potential challengers (i.e., no $\varepsilon$ term, which we explicitly model for incumbents). As long as visibility-motivation was independent of party advantage, Hypothesis 3 would be qualitatively unaffected-though its implied effect dampened.
} 


\section{Study Context}

Subnational Ugandan elections in the mid-2010s offer a good testing ground for our theory. Despite the existence of a dominant ruling party, the National Resistance Movement (NRM), Uganda's subnational governments display considerable variation in relative party advantage, which has been leveraged to study other forms of accountability in prior work (e.g., Raffler, 2022). ${ }^{13}$ Since the (re)introduction of multiparty elections in 2005, opposition parties have made meaningful inroads in some regions, owing to ties to national figures (e.g., the UPC, whose founder, former president Obote, hailed from the north) or to local power brokers, sometimes dating back to the pre-independence period (e.g., the DP in the Acholi and Baganda areas). These ties allow opposition parties to compete and sometimes outperform the NRM in candidate recruitment.

Second, political parties are neither programmatic nor ethnic-based; they compete over valence issues (Platas and Raffler, 2021) that strongly depend on representatives' effort and ability in working for their constituents, in line with our model. The Local Government Act (1997) stipulates the following job duties for councilors: legislative (e.g., passing motions), lower local government participation (e.g., attending LC3 meetings), contact with the electorate (e.g., constituent meetings), and monitoring public service provision (e.g., verifying that service delivery standards are met). Using survey data from the study area, Grossman and Michelitch (2018) document that incumbent performance on these tasks is salient for citizens.

Third, citizens have limited information about incumbent performance, especially at the district level (LC5) on which the study focuses (Buntaine et al., 2018). On the one hand, this subnational level does not attract the media attention reserved to national politics. On the other hand, districts are further away from citizens than more local government levels, such as subcounty (LC3) and village (LC1).

Citizens in Uganda's district council elect two representatives to district council in separate but simultaneous single-member plurality elections—a subcounty politician (open gender) and a

\footnotetext{
${ }^{13}$ The NRM, which has controlled the presidency since 1986 and held about 70\% of national and subnational legislative seats in 2011, maintains its hold on power through a combination of genuine popular support, bureaucratic efficiency, but also intimidation of opposition, and the use of state resources for partisan ends (Izama and Wilkerson. 2011: Golooba-Mutebi and Hickey, 2016). However, while elections show an uneven playing field (Khisa. 2019), the NRM did not engage in systematic election rigging in the study period (Hyde and Marinov. 2012). As we demonstrate in SI A, local elections, in particular, are more likely to permit genuine participation.
} 
"special woman" politician (only female) whose constituency encompasses 1-3 contiguous subcounties. We use this institutional feature in our randomization strategy.

\section{Field Experiment: Transparency Initiative}

In 2011, ACODE launched the Local Government Councilor Scorecard program in 20 districts, with the goal of strengthening electoral accountability. As part of this initiative, ACODE produces an annual scorecard capturing the performance of all district councilors (on 0-100 scale). Scorecards cover a fiscal year: the first scorecard covered July 2011-June 2012 (following the February 2011 elections), and the last scorecard covered July 2014-June 2015. ACODE collects data throughout the fiscal year, vets them every summer, and disseminates them every fall (SI, Section C).

ACODE's scorecard is divided into four components, as depicted in Figure 3. These components match the four councilor job duties discussed above. ACODE's methodology for collecting data on politicians' performance includes several steps, but they primarily rely on their reviews of the minutes of district council and lower local government sessions, service delivery and infrastructure reports, budgets, and other official records (e.g., ledgers of service providers' visitors). See SI B for a more detailed discussion of scorecard methodology and quality control.

ACODE disseminates incumbents' scores online, and at annual events at the district headquarters, which are attended by district politicians, party elites, civil servants, and local media. However, the information disseminated in these events hardly reaches voters: Grossman and Michelitch (2018) report that in 2012, only 9\% of survey respondents in the study area had heard "at least something" about the scorecard initiative.

To test whether directly informing voters about their politician performance can improve electoral accountability, ACODE, in collaboration with the research team, randomly selected half of politicians to participate in the "Intense Dissemination" (ID) program. ${ }^{14}$ Treated politicians were informed in advance and invited to attend two rounds of parish-level community dissemination events. The first set of community meetings took place in late 2013 (354 meetings, 12,949 attendees, 2012-2013 scores) and the second in late 2014 (339 meetings, 14,520 attendees, 2013-2014 scores). ${ }^{15}$

\footnotetext{
${ }^{14}$ Randomization was blocked at the district level (see SI G.1 showing good balance).

${ }^{15}$ Due to the proximity to the February 2016 election, the 2014-2015 scores were not disseminated.
} 


\begin{tabular}{|c|c|c|}
\hline PARAMETER/INDICATOR & Actual Score & Maximum Score \\
\hline 1. LEGISLATIVE ROLE & & 25 \\
\hline i) Participation in plenary sessions & & 8 \\
\hline ii) Participation in Committees & & 8 \\
\hline iii) Moved motions in Council & & 5 \\
\hline iiii) Provided special skills/knowledge to the Council or committees & & 4 \\
\hline 2. CONTACT WITH ELECTORATE & & 20 \\
\hline i) Meeting with Electorate & & 11 \\
\hline ii) Office or coordination centre in the constituency & & 9 \\
\hline 3. PARTICIPATION IN LOWER LOCAL GOVERMENT & & 10 \\
\hline i) Attendance in sub-county Council sessions & & 10 \\
\hline 4. MONITORING SERVICE DELIVERY ON NATIONAL PRIORITY PROGRAMMES AREAS & & 45 \\
\hline i) Monitoring of Health Service delivery units & & 7 \\
\hline ii) Monitoring Agricultural Projects & & 7 \\
\hline iii) Monitoring Education facilities & & 7 \\
\hline iv) Monitoring Road projects & & 7 \\
\hline v) Monitoring Water facilities & & 7 \\
\hline vi) Monitoring Functional Adult Literacy programmes & & 5 \\
\hline vii) Monitoring Environment and natural resources & & 5 \\
\hline
\end{tabular}

Figure 3: ACODE Scorecard components

In those meetings, ACODE representatives shared information on councilors' scores, and their ranking within the district. Surveys the research team conducted with a sample of attendees show these events were highly effective.

Moreover, ACODE undertook efforts to ensure politicians' performance was widely shared and salient between meetings. Posters with politicians' scores were hung in prominent places, and calendars and fliers were given to attendees to further share with neighbors. Given their visual appeal and the scarcity of calendars in this context, these items were considered valuable. Further, ACODE signed up meeting attendees to receive periodic text messages about the (absolute and relative) performance of their district councilors.

Given these activities, the ID program constitutes an improvement in levels of transparency in this context. In treatment areas, ACODE disseminated incumbent performance information to voters but also created common knowledge of incumbent's performance among incumbents and party leaders and voters. The marginal effect of the ID treatment is therefore the combined effect of informing voters and creating common knowledge around politician performance (above and beyond elite dissemination described above). Grossman and Michelitch (2018) found that the ID 
program was sufficiently powerful to change incumbent behavior. In this study, we assess the subsequent effect of sustained transparency on electoral outcomes.

We face several challenges in testing our model (itself a stylized representation of more complex decision processes). To study the effects of sustained transparency, we examine a string of mutually dependent behavioral responses. While the model allows us to specify hypotheses that account for this, nested conditional hypotheses produce thorny estimation challenges. Moreover, while successfully executing a multi-year program across hundreds of constituencies is already a herculean effort for a local NGO in a low-income country setting, our sample size yields lowerthan-ideal statistical power (SI, Section E). For this reason, we consider the evidence in terms of tendencies and patterns, assessing substantive significance and not only statistical significance.

\section{Data and Empirical Strategy}

Following our study's pre-analysis plan (see SI I on deviations), we use the following data sources: (1) an original in-person politician survey fielded several months prior to the February 2016 elections $(N=375),(2)$ electoral data from Uganda's Electoral Commission, and (3) ACODE's yearly scorecards. We construct the following variables.

Electoral Outcomes. Our primary outcome of interest is Won again, an indicator of whether the incumbent won reelection. Secondary outcomes include: Vote Share, a continuous variable [0-1] measuring incumbent's share of total valid votes; Number of Candidates, a continuous measure of the number of challengers; Effective N. of Candidates, a continuous measure of how concentrated support for the incumbent is, ${ }^{16}$ Won nomination, an indicator of whether an incumbent won (again) her party's nomination; and Ran again, an indicator of whether an incumbent chose to run for reelection. Electoral outcomes are derived from official electoral returns, except Ran again that is self-reported.

Treatment. An indicator variable that equals zero when ACODE shared the incumbent's performance scores only at district-level annual events. The Treatment equals one when ACODE addi-

\footnotetext{
${ }^{16}$ The Laakso-Taagepera measure is computed as $N=\frac{1}{\sum_{i=1}^{n} p_{i}^{2}}$, where $n$ is the number of candidates with at least one vote and $p_{i}^{2}$ is the square of their vote share.
} 
tionally disseminated the incumbent's scores at community meetings in 2013 and 2014.

Moderators. As per our model, we construct measures of two key moderating variables. The first is Performance, an indicator variable of whether the incumbent had above district median performance using the 2013-2014 scorecard. We demonstrate the robustness of our findings using the 2011-2012 scorecard (SI G.4). Scores are correlated at 0.39 over the term (SI, Section F). The 20132014 scorecard was disseminated in October-November 2014, and was the last scorecard before mid-2015, when incumbents and potential challengers had to finalize their running decision and party leaders chose their nominees. Thus, the 2013-2014 scorecard is post-treatment. By contrast, the 2011-2012 scores were produced early in the term and were not disseminated at the community level. We give more weight to the 2013-2014 scorecard because elites and citizens pay more attention to, and weigh more heavily, political information that is closer to elections (Michelitch and Utych, 2018). Bobonis, Fuertes and Schwabe (2016) similarly condition on Mayors' behavior that changed in response to prior knowledge of the timing of municipal audits' release.

The second moderator is Party advantage, which is calculated using the median vote margins for the incumbent's party using the following 2011 elections: (i) president, (ii) members of parliament, (iii) district chairperson, and (iv) district councilors. We further dichotomize party advantage using the district median value. See SI G.1 for descriptive statistics of all variables used in the empirical analysis.

\section{Empirical Strategy}

To test the effect of the intense dissemination treatment (T), conditional on the performance signal (S), we run the following OLS models for incumbent $i$ in district $j$ :

$$
y_{i j}=\beta_{1} T_{i j}+\beta_{2} S_{i j}+\beta_{3} T_{i j} \times S_{i j}+\alpha_{j}+\epsilon
$$

where $y_{i j}$ is an outcome of interest, $\alpha_{j}$ are district indicators, since randomization used districts as blocks, and $\epsilon$ is the error term. We further weight observation by the inverse of the treatment assignment probability. When the outcome is binary, the model is a linear probability model to ease interpretation. 
In some models, we adjust for a set of pre-specified politician and constituency covariates. Politician covariates include: SWC mandate (i.e., special women councilor indicator); Education (a three-category variable); Age (continuous); Motor vehicle (indicator-a proxy for wealth); NRM (indicator); Terms in office (continuous). Constituency-level covariates (from the 2014 census) include: Population (log); ELF (Ethnic-linguistic fractionalization); Literacy rate, Share agriculture employment and Poverty index. These variables help alleviate possible concerns stemming from the fact that party advantage is not randomly assigned. When we adjust for pretreatment covariates, we set missing covariate values to the mean values of the covariates in one's treatment groups and include an indicator variable that equals one for imputed values. Following our PAP, the covariates are demeaned and interacted with a treatment indicator.

Since our theory views outcomes as nested, we report estimates using the full sample as well as restricted samples defined by previous stages (for example, winning reelection conditional on running again and winning the party nomination). While adherence to our theory is closer, restricting to these samples can come at a cost in terms of statistical power (which we estimate and report in SI, Section E). Given our study's relatively small sample-size, we supplant our parametric estimates of uncertainty with simulation based randomization inference p-values (for details, see SI Section G.3). In addition, we take the view of Gerber and Green (2012, p. 63) that "a parameter falling short of the 0.05 threshold might nevertheless be important and interesting" especially if it is the "first experiment of its kind and we had no prior knowledge of the treatment effect, the estimate...would still be our best guess."

\section{Results}

Does sustained transparency to citizens improve the electoral prospects of high-performing incumbents and hurt those of low-performing incumbents? Figure 4 plots the raw data on Won Again, our main outcome of interest (Hypothesis H3a), and points to the potential efficacy of sustained transparency to strengthen electoral accountability.

Moving from raw data to a more formal analysis, in Table 2 we report tests for both H3a (where win again is conditional only on incumbent's performance signal) and H3b (where we further 
Did the incumbent win reelection $(\mathrm{H} 3 \mathrm{a})$ ?
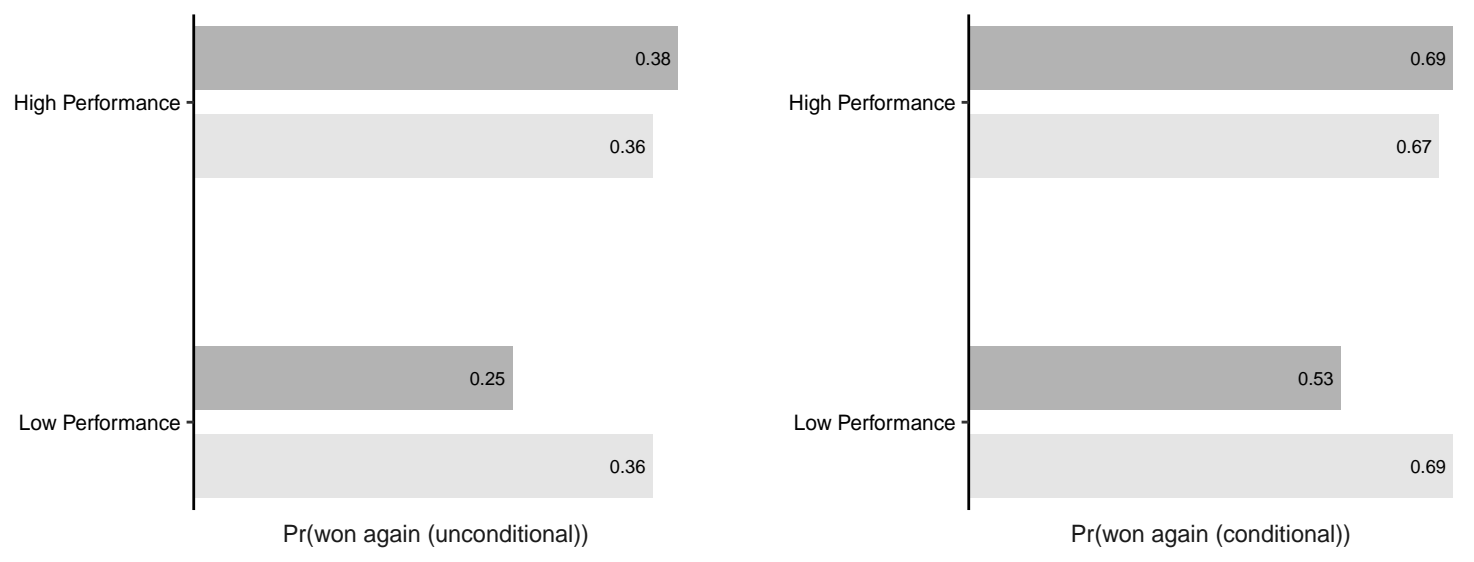

Treatment Control

Figure 4: Relationship between sustained transparency and incumbents' winning probability by performance signal. Incumbent's performance signal $s$ is proxied by the 2013-2014 score, dichotomized ( $\mathrm{s} \in\{l, h\})$ using within-district medians. Left panel sample includes all incumbents whether they stood for reelection $(n=354)$, while the sample in the right panel is restricted to incumbents who won their party nomination, excluding independents $(n=168)$.

condition by relative party advantage). The table's panels correspond to two samples: in Panel A, the sample includes all 354 partisan incumbents, irrespective of whether they chose to run for reelection; in Panel B, the sample is restricted to incumbents who won their party nomination.

Reduced-form tests of H3a indicate that in the full sample of incumbents (Panel A, column 4), sustained transparency reduced the winning probability of incumbents with a low-performance signal by $15.1 \mathrm{pp}$. (RI p-value $=0.033)$, and increases the winning probability of those with a high-performance signal by $4.3 \mathrm{pp}$. These effects are in line with H3a, though only the treatment effect for those with a low performance signal is significant at conventional levels. Results are statistically and substantively stronger when we include only incumbents who won their party nomination (Panel B, column 4). Here the treatment reduced the winning probability of lowperformance by $30.7 \mathrm{pp}$. (RI p-values $=0.012)$, and increases the winning probability of highperformance incumbents by $9.9 \mathrm{pp}$. These are substantively large effects sizes that suggest that transparency has a genuine potential to improve electoral accountability. 
In Table 2 columns 5-8, we distinguish between high- and low-party advantage. Following our model, we focus on incumbents who won their party nomination (Panel B). Consistent with $\mathrm{H} 3 \mathrm{~b}$, the positive effect of sustained transparency on the winning probability of high performers is lower (4.1 pp.) when relative party advantage is low compared to when it is high (19.8 pp.). Among low performers, instead, the negative effect of sustained transparency on winning probability is somewhat larger when relative party advantage is low (43.6 pp.) compared to when it is high (27.2 pp.), which is not consistent with $\mathrm{H} 3 \mathrm{~b}$.

The comparison between Table 2 Panels A and B helps shed light on the relative role of party leaders and voters in the nexus of transparency and accountability. For example, for low performers who nonetheless won their party nomination, the decrease in reelection probability due to greater transparency is estimated to be $30.7 \mathrm{pp}$. (Panel B, column 4), but it is $15.1 \mathrm{pp}$. in the unconditional sample (Panel A, column 4). This suggests that voters punish low performers above and beyond the potential weeding out of the party nomination process. We further explore these mechanisms and assess $\mathrm{H} 1$ and $\mathrm{H} 2$ below.

\section{Robustness}

We test the robustness of our results by using alternative measures of both signal and party advantage. First, we condition the effect of the ID program on the pre-treatment (2011-2012) scorecard. Results reported in SI, Table 3 are consistent with our model predictions, though understandably weaker (the signal dates to several years prior to the election, and as mentioned, was not disseminated down to the communities as were the 2013-2014 scores). Second, our theory is agnostic about how to operationalize high or low relative party advantage. We thus test the robustness of our results to an alternative cutoff (defining low party advantage as the bottom 60 percentile of our continuous measure, and high party advantage as the top 40 percentile). Results reported

in SI, Table 4, are stronger than those reported in Table 2. Finally, SI Figures 14:15 report results (consistent with H3) in which the party advantage moderator is continuous. 


\section{Mechanisms}

Thus far we have seen that sustained transparency can strengthen accountability by increasing the reelection of high performers and reducing the reelection of low performers. We now explore the extent to which this finding is due to incumbents (via their running choices), parties (via nomination choices), potential challengers (via entry choices), or citizens (via their vote choice).

A key advantage of the current study is the ability to track the effect of an exogenous shock to transparency throughout the accountability chain. Such analysis, however, does not come without challenges. While the reduced-form effect of greater transparency on incumbents' winning probability is causally identified, assessing the relative contribution of other actors-party elites, potential challengers and voters-requires additional assumptions. Readers can consider results in this section as informative, but suggestive.

\section{Incumbents' Running Decision}

Our theory predicts that sustained transparency decreases low performers' propensity to run again (H1a), especially when party advantage is high (H1b), and increase high performers' propensity to run again (H1a), especially when party advantage is low (H1c). Table 3 offers evidence that broadly consistent with H1a: sustained transparency reduces the running choice of a lowperforming incumbent by 7.4 pp., while leaving the running probability of high performers virtually unchanged (column 4).

Disaggregating by party advantage confirms these patterns: sustained transparency encourages running by high performers (an increase of 1.7 pp. under low party advantage and an increase of $4.9 \mathrm{pp}$. under high party advantage) and discourages running by low performers (a drop of $8.5 \mathrm{pp}$. under low party advantage and a drop of $5 \mathrm{pp}$. under high party advantage). While in line with our theory, the effects are quite noisy. However, the decline in the running propensity of low performers seems somewhat higher under low party advantage than under high party advantage and the increase in the running propensity of high performers seems somewhat higher under high party advantage than under low party advantage. This runs contrary to H1b and c. 
These estimates suggest that incumbents' running decisions are at best a secondary pathway of accountability and cannot account of the large effects on win probability reported in Table 2 . The main reason is that many low performers assigned to the ID program still run (often as independents after losing their party nomination). This is in line with the idea that non-electoral motivations (e.g., visibility and status, as captured by $\varepsilon$ in our model) play a role in incumbent running decision-making.

\section{The Behavior of Political Parties}

Did parties (via the nomination process) play a role in improving accountability? Our theory implies that transparency should encourage parties to replace poor performers and renominate high performers, irrespective of relative party advantage (H2). In Table 4, we show results both for the full sample (columns 1-4), and for the restricted sample of only those who run for reelection (columns 5-8). Since Ran again is self-reported and given that running for reelection can be endogenous to signals by party elites, these estimates should be taken cautiously.

It is important to recall that ACODE disseminates the scorecard in district events. Party elites thus have had access to incumbents' scores in both treatment and control conditions. To the extent that party elites use an NGO generated performance scorecard (signal) as a metric for effectiveness in advancing the party's agenda, this should not vary by treatment status in our setting. Instead, the ID program could change party elites' expectations of voters' behavior due to the widespread dissemination of the same performance signal that elites have already had access to.

We find some evidence that sustained transparency encourages party elites to remove low performers, but it is less consequential for high performers. The treatment reduced party renomination by $11.6 \mathrm{pp}$. for low performers, and increased it by $3.4 \mathrm{pp}$. for high performers (Table 4 . column 8). While the signs of the coefficients are consistent with our theory, their magnitudes are small relative to the estimated overall effect of transparency on incumbent winning probability. Overall, our results suggest that party elites' nomination decisions are only partially responsive to incumbent performance information. 


\section{Potential Challengers}

Did sustained transparency affects entry decisions by potential challengers? We assume that due to random assignment, the underlying number of potential challengers (an unobserved population) would be similar across treatment and control constituencies. As summarized in Table 1, we expect that transparency will have little effect on candidates' entry choices when incumbents' party advantage is relatively low. Conversely, when incumbents' party advantage is sufficiently high, we expect sustained transparency to encourage the entry of potential challengers when the signal of incumbent's performance is low, and discourage their entry when the signal of incumbent's performance is high.

Table 5 reports results for both the number of candidates and the effective number of candidates. First, as hypothesized, when party advantage is low, transparency does not encourage the entry of potential challengers, irrespective of performance signal (Table 5, Panel B, column 1). Second, when party advantage is high, sustained transparency increases the number of candidates challenging a low-performing incumbent by one candidate (RI p-value $=0.094$, Panel B, Column 2). Conversely, the number of candidates challenging a high performer drops by only 0.3 candidates. In sum, when relative party advantage is sufficiently high, some of the effect of sustained transparency on lowering the winning probability of low performers operates through strategic entry of potential challengers.

\section{Voter Behavior}

As a final step, we explore the relationship between transparency and citizens' vote choices. Consistent with our model, sustained transparency reduces the vote share of low performers when party advantage is sufficiently high (Table 5. Panel B, column 4)—when voters are faced with a higher number of alternatives. While the magnitude of the estimated drop in vote share is considerable (12.7 pp.), the effect falls below significance level (RI p-value=0.272), and so does the estimated increase in vote share for high performers, which is also smaller (4.4 pp.).

When party advantage is relatively low (Panel B, column 3), the effect of greater transparency on the vote share of low performers is modest (5.9 points), while the effect on high performers is 
larger (9.8 pp.), though these estimates are also noisy. While suggestive, our results seem to indicate that voters have been responsive to the information they received regarding the performance of their elected representative in the district government.

\section{Discussion}

We provide a novel theory of how sustained transparency improves electoral accountability and test its predictions using a field experiment in Uganda. We find that greater transparency strengthens electoral accountability and that its effect is moderated by the relative advantage of the incumbent's party: Sustained transparency (i) reduces the re-election of low performers in both highand low-party advantage constituencies and (ii) increases the reelection of high performers, but only in constituencies with relatively high party advantage.

The relative contribution of the mechanisms at play differs across high- and low-party advantage constituencies. Consistent with our model, the effect of transparency on accountability via challenger entry in the general election is stronger when party advantage is relatively high. Here, the "outsider hurdle" of a challenger beating the incumbent exceeds the "contestability hurdle" of beating other potential challengers. By favoring candidate entry and depressing voter support, transparency decreases the electoral security of low-performing incumbents. We also provide some (weaker) evidence that transparency improves accountability through party nominations choices and incumbents' running decisions (especially when party advantage is low).

Our model and findings offer important lessons for both theory and policy. Existing theoretical models of electoral accountability both overstate and oversimplify the ability of transparency to discipline incumbents, leading to the potential omission of additional potentially relevant factors in empirical work. Below, we discuss key implications of our study for future work.

First, scholarship on accountability should not overlook the role of parties' organizational strength. In weakly institutionalized electoral settings that characterize much of sub-Saharan Africa (but also in consolidated democracies), party competition at the subnational level is frequently uneven (Hiskey and Moseley, 2020). Our theory highlights how relative party advantage moderates the effect of transparency. Transparency expands the range of situations in which per- 
formance is pivotal for an incumbent's electoral fortunes and leads to the weeding out of low performers, especially at high levels of party advantage. While our theory suggests that sustained transparency can weaken local political monopolies, our results suggest that, at least in our context, the empirical relevance of this channel is limited: internal party nominations are no substitute for voter response.

Second, our study expands existing models of political accountability to include pre-election decisions by incumbents (running), parties (nominations), and potential candidates (entry). In a standard accountability model, prospective voters compare their posterior about the incumbent (which depend on transparency) with an exogenous retention cutoff, implicitly assuming that challenger entry and party nomination decisions do not respond to transparency. By weakening this assumption, our model identifies another channel through which transparency affects accountability - a channel that is crucially moderated by party advantage.

Third, our study underscores the importance of going beyond "putting out politically relevant information in the public domain," to ensure common knowledge of the information dissemination efforts among citizens and political elites well in advance of elections. In our study, the control condition is the dissemination of incumbents' performance information to district elites, so our treatment captures the effect of informing voters-and making elites aware that voters are informed-about incumbent performance.

Fourth, while incumbents respond to sustained transparency in ways that strengthens accountability (by exerting more effort and less frequently seeking reelection after a low performance signal), many low performers chose to run despite being considerably less likely to win. This points to the role of non-office motivations in candidacy: for some incumbents, visibility and status from candidacy may be as important as retaining office. In our setting, the share of visibility-motivated incumbents was larger than our priors - and an important omission from existing theories.

Future research should also consider the role of outside options (Grossman and Hanlon, 2014) in pursuit of which incumbents may choose to drop out from politics. While these instances are rare in our data, they may be more common in other settings. In addition, we do not study whether more top-down approaches would have the same response. The program we study may have been successful, in part, due to the reputation of our local NGO partner and the ongoing 
long-term engagement between the research team and local stakeholders.

Moreover, similar transparency initiatives at the national level may backfire, especially if political agents feel threatened (Humphreys and Weinstein, 2012). At the subnational level, however, party leaders might benefit from greater transparency via its effect on incumbent effort (see Proposition 1 in Appendix H.2). Perhaps tellingly, ACODE's transparency initiative did not reduce the share of seats held by the NRM. Nevertheless, incentive compatibility of transparency initiatives to political elites remains an important avenue for future research. 
Panel A: unconditional sample

\begin{tabular}{|c|c|c|c|c|c|c|c|c|}
\hline & \multicolumn{4}{|c|}{ Full } & \multicolumn{2}{|c|}{ Low PA } & \multicolumn{2}{|c|}{ High PA } \\
\hline & (1) & (2) & (3) & (4) & (5) & (6) & (7) & (8) \\
\hline \multirow[t]{2}{*}{ Treatment } & -0.049 & -0.049 & -0.120 & $-0.151^{* *}$ & -0.200 & $-0.183^{*}$ & -0.088 & 0.151 \\
\hline & $(0.049)$ & $(0.042)$ & $(0.079)$ & $(0.058)$ & $(0.116)$ & $(0.101)$ & $(0.092)$ & $0.089)$ \\
\hline \multirow[t]{2}{*}{ Performance } & & & 0.010 & -0.010 & 0.083 & 0.044 & -0.057 & 0.060 \\
\hline & & & $(0.079)$ & $(0.087)$ & $(0.145)$ & $(0.166)$ & $(0.088)$ & $.122)$ \\
\hline \multirow[t]{2}{*}{ Treatment $\times$ Performance } & & & 0.136 & 0.194 & 0.236 & 0.286 & 0.084 & .174 \\
\hline & & & $(0.124)$ & $(0.127)$ & $(0.164)$ & $(0.188)$ & $(0.143)$ & $0.150)$ \\
\hline Covariates & no & yes & no & yes & no & yes & no & yes \\
\hline RI Pval (Low Performance) & {$[0.342]$} & {$[0.354]$} & {$[0.089]$} & {$[0.033]$} & {$[0.04]$} & {$[0.068]$} & {$[0.397]$} & {$[0.184]$} \\
\hline ME (High Performance) & & & 0.016 & 0.043 & 0.036 & 0.103 & -0.004 & 0.023 \\
\hline SE (High Performance) & & & $(0.076)$ & $(0.089)$ & $(0.104)$ & $(0.14)$ & $(0.115)$ & $(0.126)$ \\
\hline $\mathrm{N}$ & 354 & 354 & 354 & 354 & 166 & 166 & 188 & 188 \\
\hline $\mathrm{R}^{2}$ & 0.07 & 0.14 & 0.08 & 0.16 & 0.15 & 0.26 & 0.15 & 0.26 \\
\hline \multicolumn{9}{|c|}{ Panel B: sample is conditional of winning party nomination } \\
\hline & \multicolumn{4}{|c|}{ Full } & \multicolumn{2}{|c|}{ Low PA } & \multicolumn{2}{|c|}{ High PA } \\
\hline & $(1)$ & $(2)$ & (3) & $(4)$ & (5) & (6) & $(7)$ & $(8)$ \\
\hline \multirow[t]{2}{*}{ Treatment } & -0.087 & -0.082 & $-0.250^{* *}$ & $-0.307^{* * *}$ & $-0.339^{*}$ & $-0.436^{* *}$ & -0.112 & -0.272 \\
\hline & $(0.065)$ & $(0.063)$ & $(0.117)$ & $(0.096)$ & $(0.166)$ & $(0.160)$ & $(0.115)$ & $(0.185)$ \\
\hline \multirow[t]{2}{*}{ Performance } & & & -0.072 & -0.105 & 0.070 & 0.006 & -0.167 & -0.216 \\
\hline & & & $(0.115)$ & $(0.123)$ & $(0.203)$ & $(0.172)$ & $(0.126)$ & $(0.207)$ \\
\hline \multirow[t]{2}{*}{ Treatment $\times$ Performance } & & & 0.298 & $0.407^{* *}$ & 0.346 & $0.476^{* *}$ & 0.257 & 0.469 \\
\hline & & & $(0.195)$ & $(0.194)$ & $(0.263)$ & $(0.212)$ & $(0.211)$ & $(0.292)$ \\
\hline Covariates & no & yes & no & yes & no & yes & no & yes \\
\hline RI Pval (Low Performance) & {$[0.246]$} & {$[0.323]$} & {$[0.031]$} & {$[0.012]$} & {$[0.022]$} & {$[0.016]$} & {$[0.504]$} & {$[0.27]$} \\
\hline ME (High Performance) & & & 0.048 & 0.099 & 0.006 & 0.041 & 0.144 & 0.198 \\
\hline SE (High Performance) & & & $(0.111)$ & $(0.127)$ & $(0.144)$ & $(0.162)$ & $(0.158)$ & $(0.154)$ \\
\hline $\mathrm{N}$ & 168 & 168 & 168 & 168 & 92 & 92 & 76 & 76 \\
\hline $\mathrm{R}^{2}$ & 0.16 & 0.25 & 0.19 & 0.29 & 0.37 & 0.48 & 0.26 & 0.48 \\
\hline
\end{tabular}

Table 2: DV: Won again. Estimates from a series of OLS models in which an indicator of whether the incumbent won reelection in 2016 is regressed on a treatment indicator interacted with a proxy measure of incumbent performance ( $\mathrm{s} \in\{l, h\}$ in the model). The performance indicator dichotomizes the 2013-2014 scorecard using the district median value as cutoff. In columns 5-8 we split the sample by relative party advantage (PA), which is dichotomized using district median values. Models include district fixed effects; standard errors are clustered at the district level. ${ }^{*} p<.10^{* *} p<.05^{* *} p<.01$ 


\begin{tabular}{|c|c|c|c|c|c|c|c|c|}
\hline & \multicolumn{4}{|c|}{ Full sample } & \multicolumn{2}{|c|}{ Low PA } & \multicolumn{2}{|c|}{ High PA } \\
\hline & (1) & (2) & (3) & (4) & (5) & (6) & (7) & (8) \\
\hline \multirow[t]{2}{*}{ Treatment } & $-0.035^{*}$ & -0.031 & -0.060 & $-0.074^{*}$ & $-0.101^{* *}$ & $-0.085^{*}$ & -0.014 & -0.050 \\
\hline & $(0.020)$ & $(0.021)$ & $(0.037)$ & $(0.039)$ & $(0.048)$ & $(0.047)$ & $(0.080)$ & $(0.079)$ \\
\hline \multirow[t]{2}{*}{ Performance } & & & 0.001 & -0.003 & -0.011 & -0.028 & 0.008 & 0.004 \\
\hline & & & $(0.035)$ & $(0.035)$ & $(0.030)$ & $(0.043)$ & $(0.077)$ & $(0.073)$ \\
\hline \multirow[t]{2}{*}{ Treatment $\times$ Performance } & & & 0.049 & 0.083 & 0.085 & 0.103 & 0.014 & 0.099 \\
\hline & & & $(0.052)$ & $(0.049)$ & $(0.066)$ & $(0.077)$ & $(0.093)$ & $(0.094)$ \\
\hline Covariates & no & yes & no & yes & no & yes & no & yes \\
\hline RI Pval (Low Performance) & [0.229] & {$[0.312]$} & [0.169] & {$[0.106]$} & [0.105] & {$[0.2]$} & {$[0.846]$} & {$[0.522]$} \\
\hline ME (High Performance) & & & -0.011 & 0.009 & -0.015 & 0.017 & 0 & 0.049 \\
\hline SE (High Performance) & & & $(0.028)$ & $(0.025)$ & $(0.049)$ & $(0.056)$ & $(0.058)$ & $(0.057)$ \\
\hline $\mathrm{N}$ & 335 & 335 & 335 & 335 & 159 & 159 & 176 & 176 \\
\hline$R^{2}$ & 0.09 & 0.12 & 0.09 & 0.13 & 0.13 & 0.23 & 0.12 & 0.20 \\
\hline
\end{tabular}

Table 3: DV: Ran again. Table reports a series of OLS models in which an indicator of whether the incumbent reported running for reelection in 2016 is regressed on a treatment indicator interacted with a binary proxy measure of performance $(s)$, as defined in Table 2. In columns 5-8 we split the sample by relative party advantage (PA), which is dichotomized using district median values. All models include district fixed effects; standard errors are clustered at the district level. ${ }^{*} p<.10^{* *} p<.05^{* * *} p<.01$ 


\begin{tabular}{|c|c|c|c|c|c|c|c|c|}
\hline & \multicolumn{4}{|c|}{ Unconditional sample } & \multicolumn{4}{|c|}{ Conditional on running for reelection } \\
\hline & (1) & (2) & (3) & (4) & (5) & (6) & (7) & (8) \\
\hline \multirow[t]{2}{*}{ Treatment } & -0.027 & -0.029 & -0.051 & -0.087 & -0.021 & -0.034 & -0.060 & -0.116 \\
\hline & $(0.060)$ & $(0.054)$ & $(0.076)$ & $(0.076)$ & $(0.072)$ & $(0.062)$ & $(0.099)$ & $(0.102)$ \\
\hline \multirow[t]{2}{*}{ Performance } & & & 0.088 & 0.072 & & & 0.076 & 0.048 \\
\hline & & & $(0.068)$ & $(0.081)$ & & & $(0.083)$ & $(0.105)$ \\
\hline \multirow[t]{2}{*}{ Treatment $\times$ Performance } & & & 0.040 & 0.104 & & & 0.070 & 0.151 \\
\hline & & & $(0.117)$ & $(0.140)$ & & & $(0.135)$ & $(0.175)$ \\
\hline Covariates & no & yes & no & yes & no & yes & no & yes \\
\hline RI Pval (Low Performance) & {$[0.618]$} & {$[0.61]$} & {$[0.504]$} & {$[0.286]$} & {$[0.721]$} & [0.58] & [0.479] & [0.195] \\
\hline ME (High Performance) & & & -0.011 & 0.017 & & & 0.01 & 0.034 \\
\hline SE (High Performance) & & & $(0.088)$ & $(0.096)$ & & & $(0.095)$ & $(0.109)$ \\
\hline $\mathrm{N}$ & 352 & 352 & 352 & 352 & 305 & 305 & 305 & 305 \\
\hline$R^{2}$ & 0.08 & 0.14 & 0.09 & 0.16 & 0.07 & 0.15 & 0.08 & 0.19 \\
\hline
\end{tabular}

Table 4: DV: Won nomination. Table reports a series of OLS models in which an indicator of whether the incumbent won her party nomination in 2015 is regressed on a treatment indicator interacted with a binary proxy measure of performance $(s)$, as defined in Table 2 . Models include district fixed effects; standard errors are clustered at the district level. ${ }^{*} p<.10^{* *} p<.05^{* *} p<.01$ 
Panel A: unconditional sample

\begin{tabular}{|c|c|c|c|c|c|c|}
\hline & \multicolumn{2}{|c|}{ Number of candidates } & \multicolumn{2}{|c|}{ Incumbent vote share } & \multicolumn{2}{|c|}{ Effective $N$. candidates } \\
\hline & (1) & (2) & (3) & (4) & (5) & (6) \\
\hline \multirow[t]{2}{*}{ Treatment } & -0.124 & 0.230 & 0.019 & -0.064 & -0.167 & 0.081 \\
\hline & $(0.324)$ & $(0.314)$ & $(0.071)$ & $(0.072)$ & $(0.236)$ & $(0.142)$ \\
\hline \multirow[t]{2}{*}{ Performance } & -0.175 & 0.084 & 0.054 & -0.075 & 0.113 & 0.042 \\
\hline & $(0.279)$ & $(0.347)$ & $(0.065)$ & $(0.087)$ & $(0.143)$ & $(0.199)$ \\
\hline \multirow[t]{2}{*}{ Treatment $\times$ Performance } & -0.396 & -0.498 & 0.117 & 0.116 & $-0.441^{* *}$ & -0.296 \\
\hline & $(0.332)$ & $(0.378)$ & $(0.092)$ & $(0.112)$ & $(0.202)$ & $(0.249)$ \\
\hline Party advantage & Low & High & Low & High & Low & High \\
\hline Covariates & yes & yes & yes & yes & yes & yes \\
\hline RI Pval (Low Performance) & {$[0.716]$} & {$[0.619]$} & {$[0.787]$} & {$[0.477]$} & {$[0.447]$} & {$[0.753]$} \\
\hline ME (High Performance) & -0.520 & -0.268 & 0.136 & 0.052 & -0.609 & -0.215 \\
\hline SE (High Performance) & $(0.221)$ & $(0.296)$ & $(0.061)$ & $(0.093)$ & $(0.169)$ & $(0.19)$ \\
\hline $\mathrm{N}$ & 114 & 112 & 114 & 112 & 114 & 112 \\
\hline$R^{2}$ & 0.59 & 0.58 & 0.47 & 0.53 & 0.55 & 0.58 \\
\hline
\end{tabular}

Panel B: sample is conditional of winning party nomination

\begin{tabular}{|c|c|c|c|c|c|c|}
\hline & \multicolumn{2}{|c|}{ Number of candidates } & \multicolumn{2}{|c|}{ Incumbent vote share } & \multicolumn{2}{|c|}{ Effective $\mathbf{N}$. candidates } \\
\hline & (1) & (2) & (3) & (4) & (5) & (6) \\
\hline \multirow[t]{2}{*}{ Treatment } & -0.135 & $0.990^{* *}$ & -0.059 & -0.127 & -0.158 & 0.476 \\
\hline & $(0.331)$ & $(0.455)$ & $(0.085)$ & $(0.118)$ & $(0.287)$ & $(0.285)$ \\
\hline \multirow[t]{2}{*}{ Performance } & -0.080 & 0.722 & 0.031 & -0.127 & 0.180 & 0.269 \\
\hline & $(0.309)$ & $(0.428)$ & $(0.057)$ & $(0.103)$ & $(0.189)$ & $(0.200)$ \\
\hline \multirow[t]{2}{*}{ Treatment $\times$ Performance } & -0.366 & $-1.295^{*}$ & $0.157^{*}$ & 0.171 & $-0.454^{*}$ & -0.560 \\
\hline & $(0.341)$ & $(0.642)$ & $(0.077)$ & $(0.156)$ & $(0.221)$ & $(0.412)$ \\
\hline Party advantage & Low & High & Low & High & Low & High \\
\hline Covariates & yes & yes & yes & yes & yes & yes \\
\hline RI Pval (Low Performance) & {$[0.754]$} & {$[0.094]$} & {$[0.495]$} & {$[0.272]$} & {$[0.572]$} & {$[0.18]$} \\
\hline ME (High Performance) & -0.500 & -0.305 & 0.098 & 0.044 & -0.612 & -0.084 \\
\hline SE (High Performance) & $(0.306)$ & $(0.581)$ & $(0.061)$ & $(0.092)$ & $(0.235)$ & $(0.377)$ \\
\hline $\mathrm{R}^{2}$ & 0.644 & 0.658 & 0.544 & 0.670 & 0.540 & 0.689 \\
\hline $\mathrm{N}$ & 92 & 76 & 92 & 76 & 92 & 76 \\
\hline$R^{2}$ & 0.64 & 0.66 & 0.54 & 0.67 & 0.54 & 0.69 \\
\hline
\end{tabular}

Table 5: DVs: number of candidates (columns 1-2); incumbent vote share (columns 3-4); and effective number of candidates (columns 5-6). Outcomes are regressed on a treatment indicator interacted with a binary proxy measure of performance $(s)$, as described in Table 2. All models include district fixed effects; standard errors are clustered at the district level. In odd (even) columns, we subset the sample such that relative party advantage is low (high). All models adjust for a pre-specified set of politician and constituency-level covariates as discussed above. ${ }^{*} p<.10^{* *} p<.05^{* * *} p<.01$ 


\section{References}

Adida, Claire, Jessica Gottlieb, Eric Kramon, Gwyneth McClendon et al. 2017. "Reducing or reinforcing in-group preferences? An experiment on information and ethnic voting." Quarterly Journal of Political Science 12(4):437-477.

Arias, Eric, Pablo Balán, Horacio Larreguy, John Marshall and Pablo Querubín. 2019. “Information provision, voter coordination, and electoral accountability: Evidence from Mexican social networks." American Political Science Review 113(2):475-498.

Bhandari, Abhit, Horacio Larraguy and John Marshall. 2021. “Able and Mostly Willing: An Empirical Anatomy of Information's Effect on Voter-Driven Accountability in Senegal." American Journal of Political Science forthcoming.

Bleck, Jaimie and Nicolas Van de Walle. 2018. Electoral politics in Africa since 1990: Continuity in change. Cambridge University Press.

Bobonis, Gustavo J, Luis Cámara R Fuertes and Rainer Schwabe. 2016. “Monitoring Corruptible Politicians." The American Economic Review 106(8):2371-2405.

Brierley, Sarah, Eric Kramon and George Kwaku Ofosu. 2020. “The Moderating Effect of Debates on Political Attitudes." American Journal of Political Science 64(1):19-37.

Buntaine, Mark T, Ryan Jablonski, Daniel L Nielson and Paula M Pickering. 2018. "SMS texts on corruption help Ugandan voters hold elected councillors accountable at the polls." Proceedings of the National Academy of Sciences 115(26):6668-6673.

Caselli, Francesco and Massimo Morelli. 2004. “Bad Politicians.” Journal of Public Economics 88(3-4):759-782.

Chong, Alberto, Ana L. De La O, Dean Karlan and Leonard Wantchekon. 2015. “Does Corruption Information Inspire the Fight or Quash the Hope? A Field Experiment in Mexico on Voter Turnout, Choice, and Party Identification." The Journal of Politics 77(1):55-71.

Cruz, Cesi, Julien Labonne and Pablo Querubin. 2017. “Politician family networks and electoral outcomes: Evidence from the Philippines." American Economic Review 107(10):3006-37. 
Cruz, Cesi, Philip Keefer and Julien Labonne. 2021. "Buying Informed Voters: New Effects of Information on Voters and Candidates." The Economic Journal 131(635):1105-1134. ueaa112.

Duggan, John and Cesar Martinelli. 2020. "Electoral accountability and responsive democracy." The Economic Journal 130(627):675-715.

Dunning, Thad, Guy Grossman, Macartan Humphreys, Susan D Hyde, Craig McIntosh and Gareth Nellis. 2019. Information and Political Accountability: A New Method for Cumulative Learning. Cambridge University Press.

Fox, Jonathan. 2007. "The uncertain relationship between transparency and accountability." Development in practice 17(4-5):663-671.

Gerber, Alan S. and Donald P. Green. 2012. Field Experiments: Design, Analysis and Interpretation. W. W. Norton \& Company, Inc.

Golooba-Mutebi, Frederick and Sam Hickey. 2016. "The master of institutional multiplicity? The shifting politics of regime survival, state-building and democratisation in Museveni's Uganda." Journal of Eastern African Studies 10(4):601-618.

Gordon, Sanford C and Dimitri Landa. 2009. "Do the Advantages of Incumbency Advantage Incumbents?" Journal of Politics 71(4):1481-1498.

Grossman, Guy and Kristin Michelitch. 2018. “Information Dissemination, Competitive Pressure, and Politician Performance between Elections: A Field Experiment in Uganda." American Political Science Review 112(2):280-301.

Grossman, Guy and W Walker Hanlon. 2014. "Do Better Monitoring Institutions Increase Leadership Quality in Community Organizations? Evidence from Uganda." American Journal of Political Science 58(3):669-686.

Gulzar, Saad. 2021. "Political Entry." Annual Review of Political Science 24(253-275).

Gulzar, Saad, Zuhad Hai and Binod K Paudel. 2021. "Information, Candidate Selection, and the Quality of Representation: Evidence from Nepal." Journal of Politics 83(4):1511-1528. 
Harding, Robin. 2015. "Attribution and accountability: Voting for roads in Ghana." World Politics 67(4):656-689.

Hiskey, Jonathan T and Mason W Moseley. 2020. Life in the Political Machine: Dominant-Party Enclaves and the Citizens They Produce. Oxford University Press.

Hollyer, James R, B Peter Rosendorff and James Raymond Vreeland. 2018. Transparency, democracy, and autocracy: Economic transparency and political (in) stability. Cambridge University Press.

Humphreys, Macartan and Jeremy M. Weinstein. 2012. “Policing Politicians: Citizen Empowerment and Political Accountability in Uganda." Unpublished manuscript .

Hyde, Susan D and Nikolay Marinov. 2012. “Which Elections Can Be Lost?" Political analysis 20(2):191-210.

Ichino, Nahomi and Noah L Nathan. 2013. “Do Primaries Improve Electoral Performance? Clientelism and Intra-Party Conflict in Ghana." American Journal of Political Science 57(2):428-441.

Izama, Angelo and Michael Wilkerson. 2011. "Uganda: Museveni's triumph and weakness." Journal of Democracy 22(3):64-78.

Izzo, Federica, Torun Dewan and Stephane Wolton. 2020. "Cumulative knowledge in the social sciences: The case of improving voters' information." Available at SSRN 3239047.

Khisa, Moses. 2019. "Shrinking democratic space? Crisis of consensus and contentious politics in Uganda." Commonwealth \& Comparative Politics 57(3):343-362.

Malik, Rabia. 2020. “Transparency, Elections, and Pakistani Politicians' Tax Compliance." Comparative Political Studies 53(7):1060-1091.

Martin, Lucy and Pia J Raffler. 2021. “Fault Lines: The Effects of Bureaucratic Power on Electoral Accountability." American Journal of Political Science 65(1):210-224.

Michelitch, Kristin and Stephen Utych. 2018. “Electoral Cycle Fluctuations in Partisanship: Global Evidence from Eighty-Six Countries." The Journal of Politics 80(2):412-427. 
Ofosu, George Kwaku. 2019. "Do fairer elections increase the responsiveness of politicians?" American Political Science Review 113(4):963-979.

Platas, Melina R and Pia J Raffler. 2021. "Closing the gap: Information and mass support in a dominant party regime." The Journal of Politics 83(4):1619-1634.

Prato, Carlo and Stephane Wolton. 2016. "The voters' curses: why we need Goldilocks voters." American Journal of Political Science 60(3):726-737.

Prato, Carlo and Stephane Wolton. 2018. “Electoral Imbalances and Their Consequences." The Journal of Politics 80(4):1168-1182.

Raffler, Pia. 2022. "Does Political Oversight of the Bureaucracy Increase Accountability? Field Experimental Evidence from an Electoral Autocracy." American Political Science Review .

Sircar, Neelanjan and Simon Chauchard. 2019. Dilemmas and challenges of citizen information campaigns: Lessons from a failed experiment in India. Cambridge University Press chapter 10, pp. 287-311.

Svolik, Milan W. 2013. "Learning to Love Democracy: Electoral Accountability and the Success of Democracy." American Journal of Political Science 57(3):685-702.

Weghorst, Keith. 2022. Activist Origins of Political Ambition: Opposition Candidacy in Africa's Electoral Authoritarian Regimes. Cambridge University Press. 